\title{
Atomic-resolution STEM and variable-temperature EELS Studies of Thermoelectric $\mathrm{Ca}_{3} \mathrm{Co}_{4} \mathrm{O}_{9}$
}

\author{
G. Yang*, Q. Ramasse**, R. F. Klie* \\ * Department of Physics, University of Illinois at Chicago, 845 W. Taylor St., Chicago, IL, 60616 \\ ** National Center for Electron Microscopy, Lawrence Berkeley National Laboratory, Berkeley, CA \\ 94720
}

The misfit-layered cobalt oxide $\mathrm{Ca}_{3} \mathrm{Co}_{4} \mathrm{O}_{9}$ exhibits outstanding physical properties including high thermoelectric power, low thermal conductivity, low resistivity and high thermal stability [1]. We utilize atomic-resolution Z-contrast imaging in conjunction with electron energy-loss spectroscopy (EELS) in aberration-corrected scanning transmission electron microscope (STEM) to characterize the local atomic and electronic structures of $\mathrm{Ca}_{3} \mathrm{Co}_{4} \mathrm{O}_{9}$.

In our study, the atomic-resolution STEM images were obtained using the TEAM0.5 instrument (FEI Titan $300 \mathrm{kV}$ TEM/STEM) and in order to minimize the electron irradiation damage, all EELS spectra were obtained using an aberration corrected VG HB 501 dedicated STEM. Figure 1a) shows an atomic-resolution $\mathrm{Z}$-contrast image of $\mathrm{Ca}_{3} \mathrm{Co}_{4} \mathrm{O}_{9}$ (taken from TEAM0.5) in the [010] orientation, clearly exhibiting the four distinct layers of varying brightness. The $\mathrm{CoO}_{2}$ layer can be seen as the brightest layer followed by the $\mathrm{CaO}, \mathrm{CoO}$ and $\mathrm{CaO}$ layer, respectively. The incommensurate structure of $\mathrm{Ca}_{3} \mathrm{Co}_{4} \mathrm{O}_{9}$ is not visible in this orientation. The atomic arrangements are consistent with the simulated Z-contrast image at the same orientation (Figure 1b), except the blurred CoO layers. It is found recently, by X-ray diffraction analysis, that the middle $\mathrm{CoO}$ layers are much complicated than all other layers, and a triple chain configuration was suggested to explain the complexity of these layers [2]. That might explain the apparent faintness of the $\mathrm{CoO}$ layers contrast in Fig. 1a. The other surprising finding is the direct visualization of $\mathrm{O}$ atomic columns in $\mathrm{CoO}_{2}$ layers. Figure 1c) shows an intensity profile taken across a $\mathrm{Co}$ and $\mathrm{O}$ atomic columns in the $\mathrm{CoO}_{2}$ layer. Here, the $\mathrm{Co}$ columns are shown as the brightest intensity peak, while the shoulders on both sides correspond to the positions of the $\mathrm{O}$ atomic columns, whose relative intensities are right for $\mathrm{O}$ compared to Co intensity using a $\mathrm{Z}^{2}$ argument [3].

Atomic-column resolved electron energy-loss spectra (taken from VG HB501) of the different layers in the $\mathrm{Ca}_{3} \mathrm{Co}_{4} \mathrm{O}_{9}$ unit-cell are shown in Figure 2. There are three main peaks in the background subtracted oxygen K-edge spectra, and all spectra are normalized to peak $\mathrm{C}$. The intensity of peak $\mathrm{A}$ in $\mathrm{CoO}_{2}$ layers are higher than that from $\mathrm{CoO}$ layers, which could be attributed to the charge transfer between the Co layers[4]. Figure 3 shows the $\mathrm{Co}$ L-edge from the $\mathrm{CoO}_{2}$ and the $\mathrm{CoO}$, respectively. By using the relationship between the $\mathrm{Co}_{3} \backslash \mathrm{L}_{2}$-ratio and the Co valence, we find that a mixed valence state exists in the in the $\mathrm{CoO}_{2}$ layers with a nominal Co valence of 3.5+, while the valence in the $\mathrm{CoO}$ layers is $3.0+$. The difference of measured $\mathrm{Co}$ valences compared with nominal oxidation states in both layers indicates a charge transfer between Co layers, which provides mobile holes to the $\mathrm{CoO}_{2}$ layer and is responsible for the high 2-dimensional electrical conductivity [5].

In our presentation we will further discuss the effects of charge transfer and Co-ion spin states transitions on the high-temperature conductivity in $\mathrm{Ca}_{3} \mathrm{Co}_{4} \mathrm{O}_{9}$ using variable temperature EELS. And also the effects of the electron irradiation damage on the microstructure of $\mathrm{Ca}_{3} \mathrm{Co}_{4} \mathrm{O}_{9}$ will be shown. 
References:

[1] A. C. Masset et al., Phys Rev B 62, 166 (2000)

[2] H. Muguerra,et al., Acta Crystallogr. Sect. B-Struct. Sci, 64, 144 (2008).

[3]S. J. Pennycook, and L. A. Boatner, Nature 336, 565 (1988)

[4] N. D. Browning et al, Physica C 212, 185 (1993).

[5] G. Yang et al, Phys. Rev. B 78, 153109 (2008).
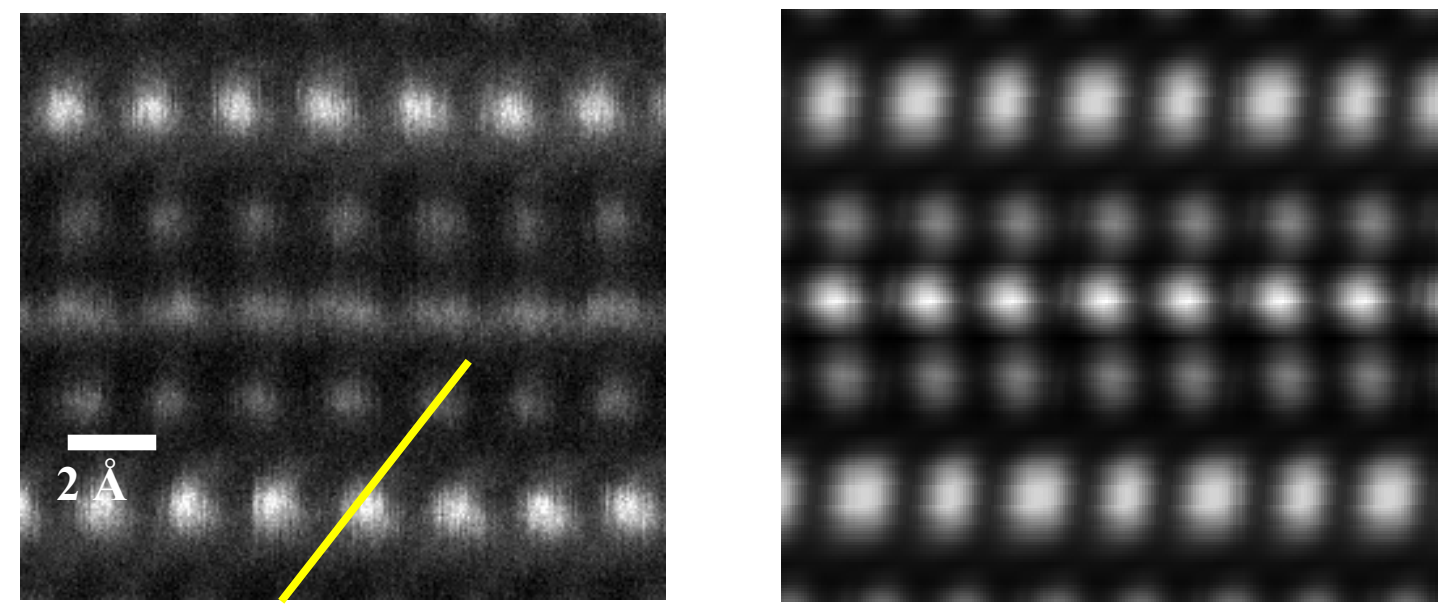

Figure 1: a) Z-contrast image of $\mathrm{Ca}_{3} \mathrm{Co}_{4} \mathrm{O}_{9}[010]$; b) Simulated Z-contrast image of $\mathrm{Ca}_{3} \mathrm{Co}_{4} \mathrm{O}_{9}[010]$

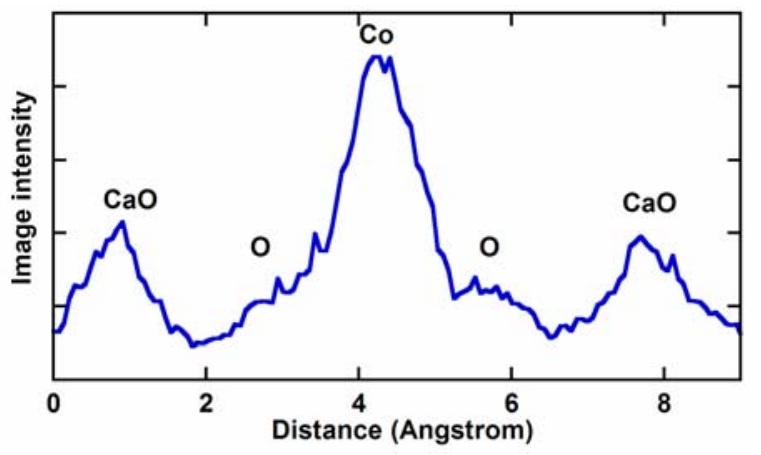

c) Intensity profile of the image across a $\mathrm{Co}$ atomic column and two adjacent $\mathrm{O}$ columns (as shown in Figure 1a)

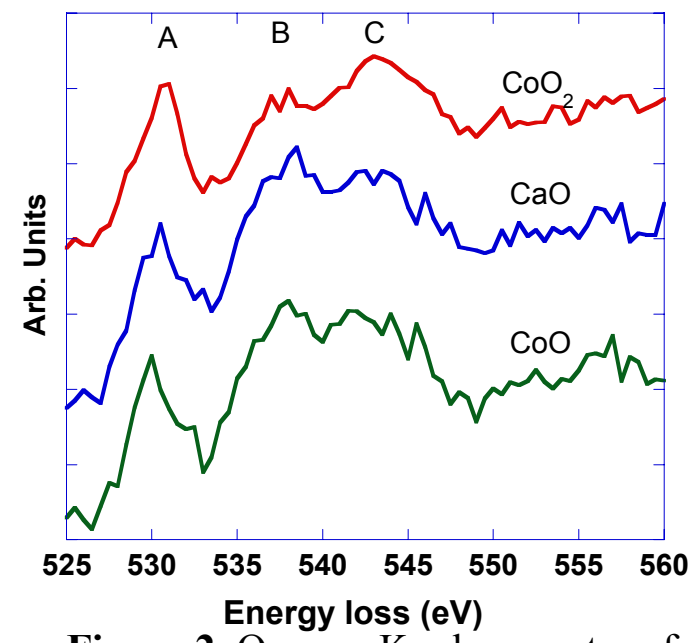

Figure 2. Oxygen K-edge spectra of different layers in $\mathrm{Ca}_{3} \mathrm{Co}_{4} \mathrm{O}_{9}$

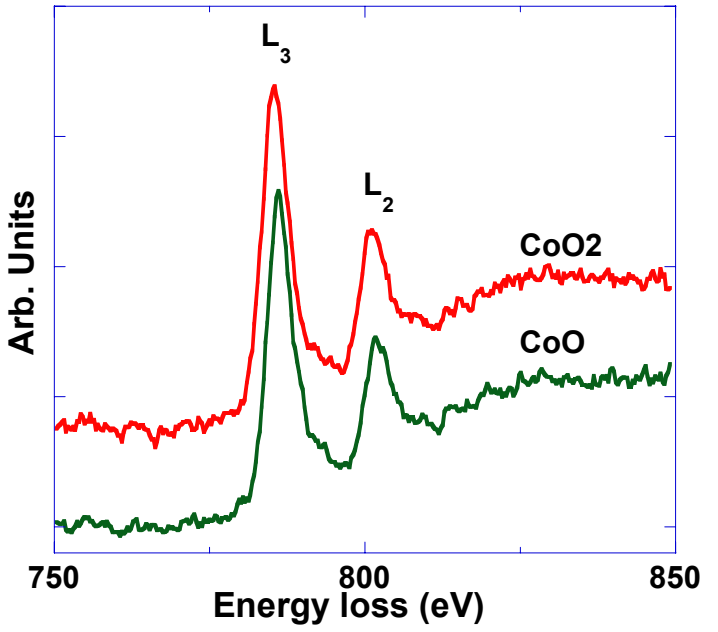

Figure 3. Co L-edges for the different Co-O layers showing the $\mathrm{Co}_{3}$ and the $\mathrm{L}_{2}$ 